\title{
Simulation as a learning method in nursing education - A case study of students' learning experiences during use of computer-driven patient simulators in preclinical studies
}

\author{
Jill Flo, Elisabeth K. Flaathen, Lisbeth Fagerström \\ Buskerud University College, Faculty of Health Sciences, Institute of Nursing Science, Norway
}

Correspondence: Jill Flo. Address: Buskerud University College, Faculty of Health Sciences, Institute of Nursing Science, Box 7053, 3007 Drammen, Norway. Email: Jill.Flo@hibu.no.

Received: October 11, 2012

DOI : $10.5430 /$ jnep.v3n8p138
Accepted: November 12, 2012

URL: http://dx.doi.org/10.5430/jnep.v3n8p138

\section{Abstract}

Background: Increasing complexity and quality requirements in the health care system require that nursing students posses good practical skills. Internationally and domestically, this has lead to an increased use of simulation in preclinical studies in nursing education. In Norway, preclinical and clinical studies constitute $50 \%$ of nursing education. Nursing students can, through simulation with a computer-driven patient manikin, train connecting theory and practice together. In this way, students can become better prepared to meet the demands of clinical studies. The aim of the study was to evaluate the nursing students' experiences connected to learning during use of a simulation manikin in preclinical studies during first-year undergraduate studies.

Methods: The study had a descriptive case study design. The evaluation included information, preparation, completion and implementation of learning goals during simulation in preclinical studies. The study encompassed two first-year classes. The data collection occurred post simulation through the means of a questionnaire given to 100 nursing students from the class of 2009 and 116 nursing students from the class of 2010. Predictive Analytics SoftWare for Vista was used for statistical analysis and the inductive content analysis of the replies to the open questions.

Results: Student evaluations show that use of simulation in preclinical studies was a positive experience and that the students have realized the day's learning goals, despite criticism of the technical equipment, for example camera angle and lighting. In total, $88 \%$ of the nursing students answered that the observation of peers was beneficial to a great or very great extent, and $89.4 \%$ experienced that reflection during debriefing was beneficial to a great or very great extent. A correlation existed between students who responded that the observation of peers was beneficial and that reflection during debriefing was beneficial. About $77.8 \%$ of nursing students were well prepared for simulation. Qualitative analysis showed that a small number of students experienced discomfort when being observed during a simulation. Feedback from peers and instructors during debriefing was experienced as being very instructive. Being able to communicate with the simulation manikin was experienced as being positive.

Conclusions: Nursing students experienced simulation as being a beneficial learning method and requested more simulation during their education. They expressed that simulation provided good practical and theoretical learning. 


\section{Key words}

Simulation, Learning methods, Students’ experiences, Nursing education

\section{I ntroduction}

Nursing education in Norway is regulated by the Act Relating to Universities and University Colleges ${ }^{[1]}$ and steered by the Curriculum Framework for Nursing Education ${ }^{[2]}$. With White Paper no. $27^{[3]}$, a new educational degree structure was introduced in Norway, and Bachelor's and Master's degrees were introduced starting in the autumn of 2002. Practical studies and skill training are mandatory and comprise $50 \%$ of the study program, in accordance with an EU directive from $2005{ }^{[4]}$. When students undergo their clinical studies, they shadow a Registered Nurse who, in addition to guiding students, is also responsible for patient treatments. The students observe many different ways to perform practical procedures during their clinical fieldwork. The field implementation of practical procedures does not always correspond to what the students have learned during instruction. If students do not receive the opportunity to link theory with practice, and in this manner become competent and effective at practical skills, this will influence the nursing care that patients receive ${ }^{[5]}$. A lack of skill development can be attributed to the conditions of nursing education, and it can happen that students graduate with a simplified view of the practical skills needed in actual nursing ${ }^{[6]}$.

Since the late 1990s, there has been a growing interest in the use of simulation in nursing education. Interest in the matter has increased in conjunction with increased quality standards in the health care system ${ }^{[7]}$. A systematic search for literature revealed that it is the United States of America and England that have the greatest experience with the use of simulation in nursing education. The use of simulation in the Nordic countries has increased in recent years. Since 2007, the University College of Buskerud (HiBu) has been in possession of "Nursing Anne", a simulation manikin used to train and simulate a number of patient evaluation and nursing procedures. The systematic use of simulation during bachelor's studies in nursing at HiBu started in 2010. During a simulation scenario, individuals can be selected to portray patients and simple to more advanced manikins can be used, including adult, child or infant models ${ }^{[8]}$. Simulation manikins have existed since the 1930s and can today be used to demonstrate everything from simple procedures to advanced scenarios ${ }^{[9]}$. Gaba ${ }^{[7, \text { p.12] }}$ defines simulations as a: "technique, not a technology, to replace or amplify real experiences with guided experiences, often immersive in nature, that evoke or replicate substantial aspects of the real world in a fully interactive fashion". Simulation is a technique that can be used to replace "real" experience and which evokes or recreates real events. Harder ${ }^{[10]}$ describes three different types of simulation: low-fidelity, middle-fidelity and high-fidelity. In low-fidelity simulation, simple manikins and skills trainers that are not computer-driven are used. In middle-fidelity simulation, manikins with heart and respiratory sound generating capabilities are used. High-fidelity simulation includes full-body computer-driven manikins, and the use of these has increased in health science education in the past few years.

During a simulation, it is possible for students to engage in "trial and error" without consequence, that is to say without harming a live patient ${ }^{[11-13]}$. Advanced biomedicine and an aging population with complex medical needs place a greater demand on the need for nursing competency ${ }^{[14]}$. Changes in health care services require advanced nursing skills ${ }^{[15]}$, and preclinical training leads to enhanced patient safety ${ }^{[16]}$. Kneebone et al. ${ }^{[17]}$ maintain that in multiple treatment environments it is becoming unacceptable for novices to train their basic skills on actual patients, because of the risk for failure and associated injuries. Models used for simulation allow students the opportunity to train safely. Confidence during the early stages of education increases and enhances students' skill mastery ${ }^{[11]}$, and students can achieve this in a preclinical situation. Students also increase their confidence through simulation ${ }^{[13]}$. Harder ${ }^{[10]}$ demonstrates in a review article that high-fidelity simulation increases students’ practical skills in the majority of studies.

\subsection{Presentation of project}

At $\mathrm{HiBu}$, a project was initiated to develop new pedagogical methods, because of the increase in complexity within the field of nursing and the increased competition for internships. Therefore, the systematic use of simulation with a 
simulation manikin started in 2010 and simulation training was introduced into first-year bachelor's nursing studies. Attendance during preclinical studies is mandatory and the preclinical studies portion of the degree program culminates in a preclinical exam graded on a pass/fail basis. When teaching methods are changed, it is important to evaluate the effect of the implemented change.

The learning goals for simulation were based on the Curriculum for Preclinical Studies used during preclinical second semester studies at $\mathrm{HiBu}$. The learning goals for simulation scenarios were presented via HiBu's digital learning platform so that all students could arrive prepared for the simulation. The learning goals were:

- Students evaluate various patient situations, plan and implement patient nursing care.

- Students are cognizant of each human being's uniqueness and worth.

- Students apply the principles of nursing documentation.

Within each main goal, diverse sub-goals were delineated, for example that students are capable of taking a patient's pulse rate, blood pressure or respiratory rate. HiBu uses a simulation manikin manufactured by Laerdal Medical for simulation scenarios. The manikin can be programmed to produce various respiratory sounds and pulse and blood pressure rates. It is also possible to insert an intravenous catheter, administer intramuscular and subcutaneous injections and practice urinary catheterization. The students are able to communicate with "the patient" through the wireless simulation of the patient voice by an instructor hidden behind a one-way screen.

A medical scenario and a clinical scenario were developed and implemented during first-year bachelor's nursing studies at $\mathrm{HiBu}$ for the class of 2009. Following the class of 2009's experience, small scenarios in the simulation room were added to the curriculum for the class of 2010 in order for students to become more familiar with the simulation manikin, including two simulation rounds equaling four scenarios. Preclinical studies are mandatory and these simulations were considered part of the preparation for the preclinical exam.

During a simulation scenario, students were divided into groups of 8-12 students who had worked with one another previously during group work. The students actively participated two and two during an actual simulation scenario. In the simulation room, one instructor was present with the students in order to provide guidance if needed. A second instructor was concealed behind a one-way screen and controlled the manikin and provided the patient voice and guided the scenario. A third instructor sat together with the remaining students who observed the simulation in a separate classroom via a video screen. Each simulation lasted approximately 20 minutes, followed by 25 minutes of reflection during debriefing. The students who participated in the actual simulation first told about their experiences and what they conceivably would have done differently. Those students observing the simulation were asked to focus on certain areas: interaction, implementation of the procedure and communication. Both the instructors and students were actively involved during debriefings.

\subsection{Aim and research questions}

The aim of this study is to evaluate nursing students' experiences connected to learning during use of a simulation manikin during first-year bachelor's studies. For the purposes of this study, students' experiences are defined as students' perceptions of and opinions on the use of simulation in nursing education.

The research questions were:

- Does the simulation contribute to the realization of learning goals and expectations of the day?

- Are the observation of peers and reflection during debriefing beneficial?

- Were the students satisfied with the information given about the simulation and were they prepared? 


\section{Methods}

\subsection{Design}

The study had a descriptive case study design that included the evaluation of simulation in a preclinical environment. Evaluation included information, preparation, implementation and realization of learning goals. Data were collected through a questionnaire that included both open-ended and close-ended questions.

\subsection{Participants}

A total of 134 nursing students from the class of 2009 and 127 nursing students from the class of 2010 registered for the preclinical exam. In total, 216 students answered the questionnaire: 100 from the class of 2009 and 116 from the class of 2010. Of these, $91.2 \%$ were female and $7.4 \%$ were male; $1.4 \%$ chose not to answer questions pertaining to gender and age. The students ranged in age from 19 to $>50$, and $50.0 \%$ of the students were younger than 22 years of age (mean 25.2).

\subsection{Evaluation instrument and data collection}

After a systematic search, we were unable to find a suitable instrument for this actual study, so a questionnaire was developed. The questionnaire included seven close-ended and 2 open-ended questions. One of the close-ended questions was excluded due to a linguistic mistake in the question. The close-ended questions included a 5-point Likert scale with the answer alternatives: very small extent, small extent, moderate extent, great extent and very great extent. It was also possible to comment on each of the seven close-ended questions. Comments related to these questions are used to support the research findings. The two open-ended questions included in the questionnaire were:

- Is there anything that you would like to emphasize as being especially good about simulation?

- Do you have any advice for us in regard to what should be improved or done differently?

Information about the study was provided to students early during the semester. The information was posted on HiBu's digital learning platform and students could contact the researchers if needed. The day of the simulation, information was provided to the students verbally in respect to anonymity, voluntary participation in the study and what the data would be used for. An instructor handed out the questionnaire directly after a simulation and debriefing. The questionnaire was filled in anonymously and returned to the instructor before the students left the classroom.

\subsection{Method of data analysis}

Predictive Analytics SoftWare (PASW) for Vista was used for statistical analysis. Descriptive statistics, crosstabulation, chi-square tests, Cronbach's alpha and correlation were used. During analysis, the answer alternatives were changed to $1=$ very small extent, $2=$ small extent, $3=$ moderate extent, $4=$ great extent and $5=$ very great extent. During calculation of significance, Fisher's exact test was used to calculate the differences between class years ${ }^{[18]}$. The Spearman's rho correlation was also used; it is recommended for use when calculating ordinal scales and in smaller studies ${ }^{[19]}$. Cohen et al. ${ }^{[20]}$ interpret correlation coefficients over 0.85 as being very strong, $0.65-0.85$ as being strong, $0.35-0.65$ as being moderate, $0.20-0.35$ as being weak and under 0.20 as being poor. Cohen et al ${ }^{[20]}$ maintain that a statistical significance of $1 \%$ and a correlation of approximately 0.40 can provide a rough prediction. The scoring options were dichotomized into 2 groups: very small and small in one group and moderate, great and very great in a second group. Inductive content analysis was used to analyze the responses to the open-ended questions, a method used for both quantitative and qualitative analyses ${ }^{[21]}$. Open responses from self-completed questionnaires can provide a different perspective on a phenomenon than frequency distribution alone.

\subsection{Ethical considerations}

In Norway, all electronic processing of personal data is in principal subject to an obligation to report or licensing. However, according to §7-20 in the Norwegian regulations relating to the processing of personal data, the Personal Data 
Act ${ }^{[22]}$, it is possible to process personal data without reporting it, provided that such occurs under the auspices of the Act Relating to Universities and University Colleges ${ }^{[1]}$. The evaluation of an educational program is a natural part of a university's activities, as delineated in the Act Relating to Universities and University Colleges ${ }^{[1]}$. The heads of the Institute of Nursing Science, Faculty of Health Sciences, HiBu gave their permission for this study.

\section{Results}

The student evaluations ( $\mathrm{n}=216$ ) showed that the students considered the use of simulation in preclinical studies to be a positive experience. However, the study did show some deviation in regard to some of the questions (see Table 1).

Table 1. Student evaluation of the close-ended questions

\begin{tabular}{llll}
\hline & Number $=\mathbf{n}$ & Mean & Standard deviation \\
\hline Satisfied with the information & 212 & 3.82 & .808 \\
Prepared for the day & 215 & 3.37 & .842 \\
Observation was beneficial & 209 & 4.28 & .679 \\
Reflection during debriefing was beneficial & 215 & 4.31 & .663 \\
The day's learning goals were achieved & 214 & 3.86 & .599 \\
Met expectations & 214 & 4.08 & .737 \\
\hline
\end{tabular}

\subsection{Expectations and learning goals}

From a total of 214 (99\%), 84.3\% of students answered that their expectations for the day had been met to a great or very great extent: $12.0 \%$ answered moderate extent and $2.8 \%$ answered small or very small extent. There was no significant difference seen between the class years.

The class of 2009 was familiar with the learning goals before they came to school on the simulation day. The class of 2010, in addition to familiarizing themselves with the learning goals, had cases presented to them so that they could better prepare for the day. This change was made following a review of the comments that the class of 2009 made on their evaluation forms.

Of the 214 (n=216) students who answered the question, all except two answered that they had realized the day's learning goals to a moderate, great or very great extent (see Figure 1). No significant difference was seen between the class years.

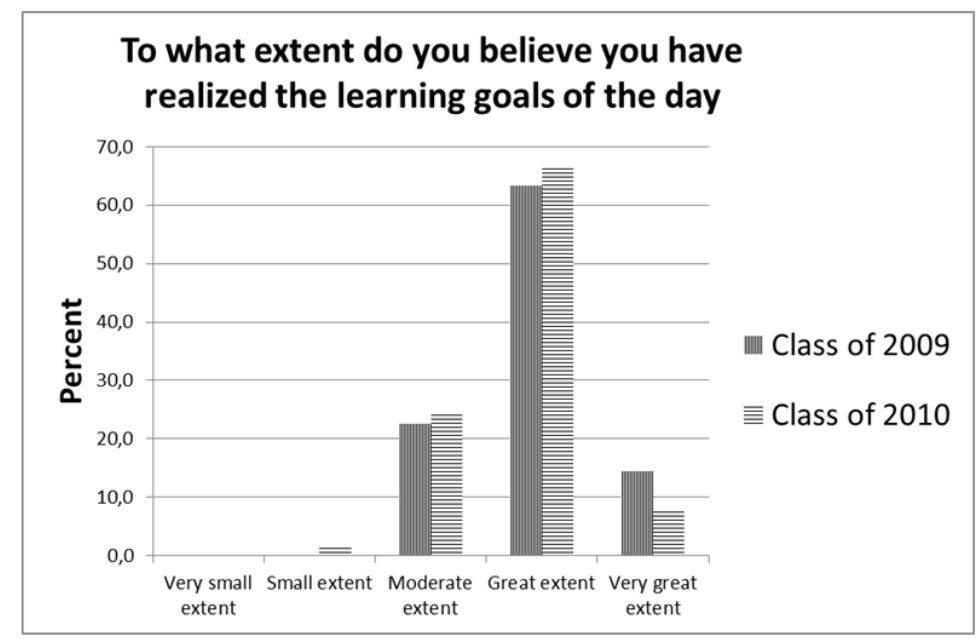

Figure 1. Distribution between class years in regard to the question of whether the day's learning goals were realized 


\subsection{Observation of peers and reflection during debriefing}

Of 216 students, 88\% answered that the observation of their peers was beneficial to a great or very great extent (see Figure 2). No significant difference was seen between the class years.



Figure 2. Distribution between class years in regard to the question of whether observation of peers was beneficial

The students (89.4\%) experienced reflection during debriefing to be beneficial to a great or very great extent. No significant difference was seen between the class years (see Figure 3).

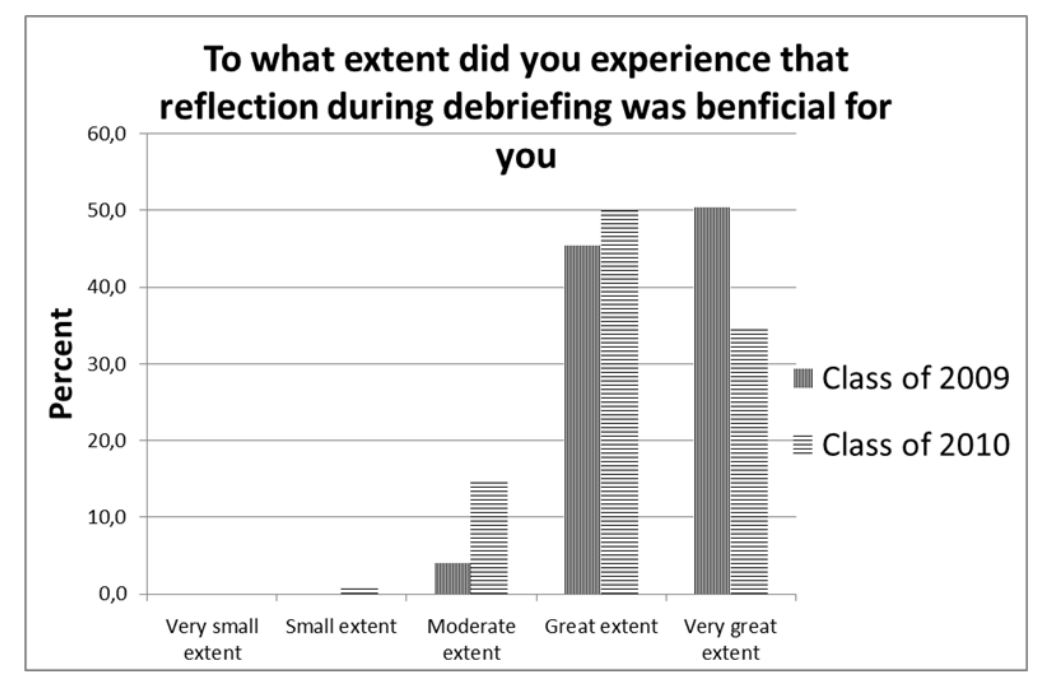

Figure 3. Distribution between class years in regard to the question of whether reflection during debriefing was beneficial

\subsection{Correlation between the various questions}

A clear correlation could be ascertained between the students who answered that the observation of peers was beneficial and that reflection during debriefing was beneficial. The students' perception that reflection during debriefing was beneficial correlated to expectations of the day being met. The perception of having met the day's learning goals correlated to that expectations were met (see Table 2). 
Table 2. Correlation between the various questions.

\begin{tabular}{|c|c|c|c|c|c|c|}
\hline & $\begin{array}{l}\text { Question } 1 \\
\text { Satisfied with } \\
\text { information }\end{array}$ & $\begin{array}{l}\text { Question } 2 \\
\text { Was } \\
\text { prepared }\end{array}$ & $\begin{array}{l}\text { Question } 4 \\
\text { Observation of } \\
\text { peers }\end{array}$ & $\begin{array}{l}\text { Question } 5 \\
\text { Reflection during } \\
\text { debriefing }\end{array}$ & $\begin{array}{l}\text { Question } 6 \\
\text { Realized day's } \\
\text { learning goals }\end{array}$ & $\begin{array}{l}\text { Question } 7 \\
\text { Expectations } \\
\text { of day met }\end{array}$ \\
\hline Question 1 & & & & & & \\
\hline $\begin{array}{l}\text { Satisfied with } \\
\text { information }\end{array}$ & & $.226 * *$ & $.186 * *$ & $.236 * *$ & $.221 * *$ & $.305^{* *}$ \\
\hline $\begin{array}{l}\text { Question } 2 \\
\text { Was prepared }\end{array}$ & $.226 * *$ & & .099 & .077 & $.322 * *$ & $.193^{* *}$ \\
\hline $\begin{array}{l}\text { Question } 4 \\
\text { Observation of peers }\end{array}$ & $.186^{* *}$ & .099 & & $.564^{* *}$ & $.367 * *$ & $.452 * *$ \\
\hline $\begin{array}{l}\text { Question } 5 \\
\text { Reflection during } \\
\text { debriefing }\end{array}$ & $.236 * *$ & .077 & $.564 * *$ & & $.377 * *$ & $.465 * *$ \\
\hline $\begin{array}{l}\text { Question } 6 \\
\text { Realized day's learning } \\
\text { goals }\end{array}$ & $.221^{* *}$ & $.322 * *$ & $.367 * *$ & $.377 * *$ & & $.462 * *$ \\
\hline $\begin{array}{l}\text { Question } 7 \\
\text { Expectations of day met }\end{array}$ & $.305^{* *}$ & $.193 * *$ & $.452 * *$ & $.465^{* *}$ & $.462 * *$ & \\
\hline
\end{tabular}

$* * p<.01 ; * p<.05$

From this material we see a moderate correlation between students who perceived that they benefited from reflection during debriefing (Question 5) and the observation of peers (Question 4).

\subsection{I nformation and preparation for the day}

In total, 212 (98.1\%) students answered the question on information given about the simulation day. 17.1\% were very greatly satisfied, $51.9 \%$ were greatly satisfied and $24.5 \%$ were moderately satisfied with the information given. Only $4.7 \%$ answered that they were satisfied to a small or very small extent. A significant difference was seen between the class years (Fisher's Exact Test $=.046$ ).

It was expected that the students were prepared for the simulation day, were acquainted with the learning goals associated with the day and were familiar with the various procedures and nursing skills needed during the actual simulation scenario. From a total of 215 (99.5\%), 77.8\% answered that they were prepared for the day to a moderate or great extent. No significant difference was seen between the class years in regard to the question of whether respondents were prepared.

\subsection{Students' experiences of simulation and suggestions for change}

In total, 58 students $(n=100)$ from the class of 2009 and 67 students $(n=116)$ from the class of 2010 answered the open-ended question about what was especially good about simulation. When asked for advice, 39 students from the class of 2009 and 67 from the class of 2010 answered the question, "What is especially good about simulation"? The following categories were emphasized here: "good learning”, "reflection and feedback during discussion group" and "communication”.

"You learn a lot, it is beyond a doubt, continue with this"

Simulation was also perceived as being good preparation for the practical exam. Students viewed it as a good practice method that provided good training and improvement of skills.

"Instructive and you get to test your skills more than normally"

"Very good learning, terrifically good" 
"Very good to be part of the simulation. You become conscious of what you are doing in a whole other way".

Many students perceived the observation of a simulation scenario as being beneficial. All of the students observed at least one simulation.

"You appear to learn a lot from observing others"

"Even if you yourself are not in the simulation you learn a lot by watching others"

Many students were positive towards reflection and feedback during debriefing. The students were of the opinion that receiving feedback from both their peers and instructors was very instructive.

"Good that you see one another and can give feedback - provide reflection and ask yourself questions"

“That you have the opportunity to receive feedback from someone that carefully followed something you did”

Students expressed that it was positive that the manikin could communicate. They were then able to practice their communication skills, and could in this manner practice answering various questions.

"You enter into a more real situation than with just regular manikin, think more about why we do what we do"

“Communication training, realistic situation, unpredictable questions, serious topics that are raised”

The following categories emerged from the analysis of the second open-ended question, which emanated from what should be done better or differently: "more simulation", "more information ahead of time" and "better technical equipment". The students wished for more use of simulation and were of the opinion that everyone should be given the opportunity to experience a simulation.

"This learning is so beneficial that it should be used more. Wish I could train more with the simulator, a lot more!!”

"We could have had more simulation throughout the year so that we had become more confident about procedures and working in a stressful situation”

A small number of students were of the opinion that it should be voluntary to participate in an actual simulation, because of nervousness. Others experienced discomfort when being observed. The desire for more information prior to the simulation was seen, especially among the class of 2009. Criticism of the technical equipment was also seen, primarily in regard to the sound and camera angles, yet despite such criticism, the experience was positive.

\footnotetext{
"Better sound and camera angle”

"Equipment that works properly is important”
}

\section{Discussion}

The aim of this study was to evaluate nursing students' experiences connected to learning during use of a simulation manikin during first-year bachelor's studies.

The results of our study show that students experienced good learning outcomes. The students perceived the observation of peers and reflection during debriefing as being especially beneficial. 
There were significant differences between the class years in terms of how satisfied students were in relation to the information provided. The class of 2010, which received more information prior to the simulation, was more satisfied than the class of 2009. The students in the class of 2010 were provided cases ahead of time and, in addition, they had familiarized themselves with the simulation manikin during the course of the semester. They had also practiced a simulation scenario prior to the actual simulation day. Information is important for good learning outcomes and for the reduction of stress ${ }^{[23]}$.

In both class years, the majority answered that they had prepared for the simulation to a moderate or great extent. The results of a study by Kiat et al ${ }^{[12]}$ show that a good simulation result requires, among other things, that students are well prepared.

In his social cognitive theory, Bandura ${ }^{[24]}$ maintains that human beings can learn by observing, something that he calls observational learning/modeling. That people learn by observing and that learning involves an internal reward, that is to say that students feel pride and satisfaction, are two of the main points in Bandura's theory. In our study, a moderate correlation between the students who answered that they found the observation of peers to be beneficial and those that answered that reflection during debriefing was beneficial was found. The students experienced the reflection and feedback during debriefing as being very instructive. The results of our study are supported by results seen in other studies ${ }^{[23,25]}$.

Those students who responded positively to these two questions also answered that they had achieved the day's learning goals and that their expectations of the day had been met (see Table 2). There are several factors that affect the modeling process, among others that learning requires concentration and that distraction has a negative effect. Technical problems such as poor lighting or problems with camera angles were found to be distractions in our study. Despite such distractions, however, the students experienced good learning.

Nursing education requires a three-dimensional view of knowledge, which consists of scientific, practical and ethical knowledge ${ }^{[26]}$. Nursing students learn practical skills through both theoretical and practical instruction and skill training. Ethical reflection over clinical situations is also of great importance, because caring for human beings is not value neutral ${ }^{[27]}$. During preclinical skill training, students must work with all three knowledge domains. Kiat et al ${ }^{[12]}$ conclude in their study that simulation is an enjoyable way to learn while at the same time theory and practice are combined, but that it requires that learning tools are used properly. The students in our study also indicated that the simulation was instructive and that they were able to test their skills more than normally. They also reported that they were aware of what they did in a different way. This corresponds to the results seen in a study by Baxter et al ${ }^{[28]}$. In a study by Wotton et al ${ }^{[25]}$, third-year nursing students practiced simulation with an advanced manikin, a SimMan 3G. The results from this study showed that over $90 \%$ of students were satisfied with working with the high-fidelity simulation manikin and the various scenarios that this manikin provided. In Kiat et al ${ }^{[12]}$, who evaluated second-year nursing students, simulation was found to be a good learning method. It was also seen that self-confidence increased when students were able to make mistakes without harming an actual patient. The students in our study indicated that they learn from their mistakes.

At the end of their first year at $\mathrm{HiBu}$, nursing students must take and pass a preclinical exam in order to continue on to second-year clinical studies. The year before simulation was introduced at $\mathrm{HiBu}$, the failure rate was relatively high for this preclinical exam. For the class of 2009, the first to experience simulation, this rate decreased by $6 \%$ and for the class of 2010 the rate was reduced by a further $10 \%$. This may indicate that simulation increases the students' learning outcomes.

\section{Methodological considerations}

Through use of a questionnaire, it is possible to reach many respondents in a short time. This can be an advantage in this study, in that we had many students who were going to experience simulation. The high response rate was probably achieved because the questionnaire was distributed immediately after the simulation and debriefing. One of the study 
researchers had taught a lot during the course of the year and was well-known among the students, which may have influenced the students' participation in the study and question responses.

The summative questionnaire was specifically developed for this study. No pilot study was conducted to test the questionnaire. This may be a weakness. Another strength of this study may be that students were given the opportunity to comment on each question and that the questionnaire included two open-ended questions where students could emphasize what was good with simulation and what could be improved or done differently.

The researchers together conducted the inductive content analysis of the responses from the two open-ended questions. According to Malterud ${ }^{[29]}$, it may be beneficial to subject the material to different views, and in this manner reveal different angles and focus, which may improve the utilization of the material.

\section{Conclusion}

Simulation has a good learning effect and students are satisfied with the pedagogical method. It would appear that simulation can help students become better prepared to meet the demands of a clinic. According to the results of this study, instruction through the use of simulation should be further developed throughout all three years of the bachelor's program, and systematic and continued research is therefore necessary.

So that the outcome of the method is the best possible, advanced technical equipment is required. It is important that in the future the camera has a wide-angle camera lens and zoom capabilities and, eventually, that there are several cameras in use during a simulation. Microphones and speakers must provide good sound to the classroom so that the simulation observers are able to hear what is being said.

\section{References}

[1] Kunnskapsdepartementet [KD] Lov om universiteter og høgskoler [Act Relating to Universities and University Colleges]. 2005: 15.

[2] Kunnskapsdepartementet [KD] Rammeplan for sykepleierutdanning [Curriculum Framework for Nursing Education] 2008.

[3] Det kongelige kirke-, utdannings- og forskningsdepartement; 2000-2001. St.meld.nr.27. Gjør din plikt - Krev din rett. Kvalitetsreform for høyere utdanning. [Do your duty - Claim your rights. The Quality Reform of Higher Education].

[4] EU direktiv (2005/36) Gjensidig godkjenning av kvalifikasjoner. [Directive on the Recognition of Professional Qualifications].

[5] Morgan, R. Using clinical skills laboratories to promote theory-practice integration during first practice placemen: an Irish perspective. Journal of Clinical Nursing. 2006; 15: 155-161. http://dx.doi.org/10.1111/j.1365-2702.2006.01237.x

[6] Bjørk, I. Nyutdannede sykepleiers manglende praktiske sykepleieferdigheter. [Newly graduated nurses' lack of practical nursing skills] Klinisk sygepleje. 2006; 20(4):23-30

[7] Gaba, D. The future vision of simulation in health care. Quality and safety in Health care. 2004; 13 (Suppl 1): 2-10. http://dx.doi.org/10.1136/qshc.2004.009878

[8] Galloway, S. Simulation techniques to bridge the gap between novice and competent healthcare professionals. Online Journal of Issues in Nursing. 2009 May; 14(2): 1-9. http://dx.doi.org/10.3912/OJIN.Vol14No02Man03

[9] O’Donnell, J., Goode, J. S. Jr. Simulation in nursing education and practice. I: manual of simulation in healthcare, Riley, H, R. (red) 2008; Oxford University Press.

[10] Harder, N. Use of simulation in Teaching and Learning in Health Sciences: A Systematic Review. Journal of Nursing Education. 2010; 49(1). http://dx.doi.org/10.3928/01484834-20090828-08

[11] Strand, I, Nåden, D, Slettebø, Å. Students Learning in a Skills Laboratory. Vård i Norden. 2009; 93(29): 18-22

[12] Kiat, T. K., Mei, T.T.T, Nagammal, S, Jonnie, A. D. A. A review of learners' experience with simulation based training in nursing. Singapore nursing Journal. 2007; 34(4).

[13] Baillie, L. \& Curtizio, J. Students' and facilitators' perceptions of simulation in practice learning. Nurse Education in Practice. 2009; 9: 297-306. http://dx.doi.org/10.1016/j.nepr.2008.08.007 
[14] Bartel Jean E. Education Article: Educating nurses for the 21st century. Nursing \& Health Science. 2005; 7(4): 221-225. http://dx.doi.org/ 10.1111/j.1442-2018.2005.00249.x

[15] Fagerström, L. Developing the scope of practice and education for advanced practice nurses in Finland. International Nursing Review. 2009; 56: 269-272. PMid:19646179 http://dx.doi.org/10.1111/j.1466-7657.2008.00673.x

[16] Flanagan, B, Nestel D, Josep M. Making patient safety the focus: crisis resource management in the undergraduate curriculum. Medical Education. 2000; 38(1): 56-66. http://dx.doi.org/10.1046/j.1365-2923.2004.01701.x

[17] Kneebone, R.L, Scott, W, Darzi, A, Horrocks, M. Simulation and clinical practice: strengthening the relationship. Medical Education. 2004; 38: 1095-1102. http://dx.doi.org/10.1111/j.1365-2929.2004.01959.x

[18] Pallant, J SPSS - Survival manual. Allen \& Unwin, Australia; 2001

[19] Polit, D., Beck, C. Nursing research: principles and methods. Lippincott Williams \& Wilkins 2004; Philadelphia

[20] Cohen, L., Manion, L., Morrison, K. Research Methods in Education 2011; Routledge. London \& New York.

[21] Elo, S \& Kyngäs, H. The qualitative content analysis process. Journal of Advanced Nursing. 2008; 62(1): $107-115$. http://dx.doi.org/10.1111/j.1365-2648.2007.04569.x

[22] Personopplysningsforskriften [Personal Data Regulation] 2000-12-15 nr 1265

[23] Gundrosen, S, Engesnes, H. Medisinsk simulering - et møte mellom utdanning og praksisfelt. [Medical simulation - a meeting between education and the field of practice] Inspira. 2010; 3: 14-18.

[24] Bandura, A. Self-efficacy, the exercise of control. 1997; New York

[25] Wotton, K., Davis, J., Button, D., Kelton, M. Third-Year Undergraduate Nursing Students’ Perceptions of High-Fidelity Simulation. Journal of Nursing Education. 2010; 49(11). http://dx.doi.org/10.3928/01484834-20100831-01

[26] Fagerström, L. Den tredimensionella kunskapssynen som epistemologisk grundsyn.[The three-dimensional view of knowledge as epistemological ethos] I: Avancerad klinisk sjuksköterska. Fagerström, L. 2011; Studentlitteratur, Lund.

[27] Jahren Kristoffersen, N. Sykepleie - kunnskap og kompetanse. [Nursing - knowledge and competence] I: Grunnleggende sykepleie 1, Sykepleiens grunnlag, rolle og ansvar. [Foundations of Nursing 1, Nursing basis, role and responsibilities] 2011; Gyldendal akademisk.

[28] Baxter, P., Akhtar-Danesh, N., Valaitis, R., Stanyon, W., Sproul, S. Simulated experiences: Nursing students share their perspectives. Nurse Education Today. 2009; 29: 859-866. http://dx.doi.org/10.1016/j.nedt.2009.05.003

[29] Malterud, K. Kvalitative metoder i medisinsk forskning. [Qualitative Methods in Medical Research] 3. utg. 2011; Universitetsforlaget. 